\title{
Development of a Measure: Reasons of Social Networking Sites Use
}

\author{
Samira Ranaiey ${ }^{1}$, Mohammad Reza Taghavi ${ }^{2} \&$ Mohammad Ali Goodarzi ${ }^{2}$ \\ ${ }^{1}$ Department Of Clinical Psychology, Shiraz, Iran \\ ${ }^{2}$ Department Of Clinical Psychology, Shiraz University, Shiraz, Iran
}

Correspondence: Samira Ranaiey, Department Of Clinical Psychology, Shiraz, Iran. E-mail: Samira_ranaie@yahoo.com/Mtaghavi@rose.shirazu.ac.ir/mgoodarzi@rose.shiraz.au.ir

Received: January 12, 2016

Accepted: February 25, 2016

Online Published: March 9, 2016

doi:10.5539/mas.v10n6p141

URL: http://dx.doi.org/10.5539/mas.v10n6p141

\begin{abstract}
Because of increased attention to PIU (Problematic Internet Use), some measure had been made, but they seem to be

Inadequate, due to new issue of the internet interactions. Therefore the necessity and importance of

Standard, valid and reliable tools to assess PIU and the related behaviors are clear.

This paper presents results of a study that develops a measure of Reasons of Using Social Networking Sites (S.N.S). The reasons were based on an article by Morahan - Martin and Schumacher. The reasons were arranged as a questionnaire. This questionnaire was completed by 156 volunteer students of Shiraz University. The results indicated that Reasons of S.N.S Use Scale is both reliable and valid. The result of factor analysis showed that two dimensions (Positive and Negative reasons of S.N.S use) explains total variance acceptably.
\end{abstract}

Keywords: social networking sites, internet behaviors scale, validity, reliability, problematic internet use

\section{Introduction}

Many studies had documented that social Networking Sites (S.N.S) has pathological effect on its users. Problematic Internet use (PIU) is a multi-dimensional syndrome, causing cognitive and behavioral symptoms, which results in negative, social, academic and professional consequences. (Caplan, 2002; Caplan 2003; Davis, 2001; Morahan - Martin, Schumacher, 2003)

In recent years due to increased attention to PIU, some tools had been made for its evaluation that seem as inadequate, which is probably due to new issue of the virtual world in the field of psychology. The importance of new and efficient tools for psychological research in the virtual world increasingly felt.

In 2003, Morahan-Martin and Schumacher in a survey about differences between lonely and non-lonely over reasons of internet use suggested 17 different reasons for internet use.

The paper then was used as a source repeatedly by researches (including The Author) but no validity and reliability for Reasons of Internet Use was reported. In this article we try to set that 17 reasons as a scales and evaluate reliability and validity and find sub-dimension of this scale. (This scale was used in survey that conducted by Author, titled as: "The Effect of loneliness on social Networking sites and its related behaviors". The article was submitted to Global Journal of Health science and the submission was accepted).

\section{Literature Review}

A number of scholars have noted the need for theoretical accounts, along with valid and reliable tools, to evaluate how psychological wellbeing associated with PIU. One of the tools which was used in a study conducted by Caplan(2007) is "Negative outcome of internet use", The Survey items used to operationalize negative outcome, associated with one's internet use, were drawn from measures employed in previous studies (Caplan, 2002; Caplan 2005; Morahan-Martin, Schumacher 2003). Participants extend their agreement on a scale from 1 to 5 . (strongly disagree to strongly agree), with three statement indicating that they had experienced negative out come due to their internet use. In that study reliability coefficient for negative outcomes reported $\alpha=0.70$.

Preference for online social interaction (Leung, 2011) was measured by using 13 item based on Caplan(2002, 2003) studies on the preference for online social interaction (Leung, 2011). A 5 point Licart type scale was used 
$1=$ strongly disagree and $5=$ strongly agree. Sample items included feel safer relating to: "having online interactions rather than face to face", "Treated better online than in face to face relationship", "More confident socializing online than offline", "More comfortable with computer than people" "I am willing to give up some of my face to face relationship to have more time for My online relationship" and "I am happier being online than I am offline" Reliability alpha was as high as, 0.83 .

To assess Facebook Groups uses and gratifications respondents were given a list of 16 statements regarding Face book group (park et al, 2009) They rated their level of agreement with specific reasons for using Facebook groups including information, acquisition about campus community, entertainment, recreation, social interaction with friends and family and peer pressures self-satisfaction (1 strongly agree, 6 strongly disagree).

The statements were adapted from cluster of the categorized dimension describing online group participants (Lin HF 2006; Rinding, Gefen, 2004).

Addictive tendencies scale (Wilson et al, 2010) based on previous research (Walsh et al, 2007; Ehrenberg, et al, 2008). The addictive tendencies scale $(\alpha=0.76)$ Comprised three items measuring level of salience: one of the first thing I do each morning is log on to a Social Networking Sited (e.g. My space or Facebook), withdrawal (I feel lost when I cannot access my social networking site (e.g. My space or Facebook) and loss of control (I find it hard to control my use of social networking sites (e.g. my space or Facebook).

These were some examples of tools which had been using by researchers to examine problematic Internet Use (PIU).

This study attends to arrange the positive and negative reasons of using S.N.S (due to submission) as a scale, and evaluate reliability and validity.

\section{Method}

\subsection{Participant}

Reasons for internet use scale were given to 156 Shiraz university students. Of these $146(93.6 \%)$ had experienced S.N.S use and were include in the research. $108(62.2 \%)$ were female and $42(26.9 \%)$ were male. The sample included 11(7.1\%) Freshmen, 34 (21.8\%) Sophomore, 30 (19.2\%) juniors, 6 (3.8\%) Seniors, 41 (26.3\%) graduate student and 31 (19.9\%) PHD students. Mean age of participants was 24.59 (S.D= 5.34). Participants had reported average weekly use as 18.01 hours $(\mathrm{SD}=20.39)$.

\subsection{Measure}

The questionnaire completed by the participants, included demographic characteristic, S.N.S experience, Reasons for S.N.S use Scale.

Those participants who had S.N.S use experience included in the study.

\subsection{Item Origin - Selection Process}

The reasons were chosen based on the 17 reasons presented by Morahan - Martin - Schumacher (2003). The arranged scale includes 17 Likert - type question (regarding reasons) and four-point score with 1: Strongly disagree and 4 strongly agree.

\subsection{Psychometric Support}

For Evaluating reliability: coefficient $\alpha$ and test -retest will be conducted. For evaluation of validity explanatory factor analysis and convergent and discriminant validity will be conducted.

\subsection{Ethics}

Ethical approval: All procedures performed in studies involving human participants were in accordance with ethical standards of institutional and national research committee with the 1964 Helsinki declaration and its later amendments or comparable ethical standards.

Informed consent: Informed consent was obtained from all individual participants included in this study.

\section{Results}

\subsection{Reliability}

\subsubsection{Coefficient $\alpha$}

Reliability $\alpha$ was as high as $\alpha=0.786$ for negative reasons and $\alpha=0.813$ for positive reasons. 


\subsubsection{Test - Retest Method}

The scale of Reasons of Social Networking Sites Use was given to 30 Shiraz university students and after 3 weeks the same test was conducted. Table 4-1 provides the descriptive statistics (Mean \pm SD) for subscales scores. We used correlated samples t-test to formally test whether means are similar. A Pearson's correlation is computed to assess test-retest reliability. Note means are similar, and this table indicates that the correlation of the two scores (per subscale) is high and positive so there is strong support for the test-retest reliability.

Table 1. Results of test - retest

\begin{tabular}{lllllll}
\hline Dimensions & First time & Second time & The difference between first and second time & P value & Correlation p- value \\
& & & & & \\
\hline Positive reasons & $19.78 \pm 3.68$ & $19.59 \pm 4.12$ & $.19 \pm 1.66$ & .568 & $.915(.000)$ \\
Negative reasons & $22.26 \pm 5.72$ & $22.11 \pm 6.57$ & $.15 \pm 4.03$ & .85 & $.794(.000)$ \\
\hline
\end{tabular}

\subsection{Validity}

\subsubsection{Factor Analysis}

Exploratory factor analysis (Principal component method with Varimax rotation) was conducted, with two dimension (Positive and negative reasons of S.N.S Use). These two dimensions explain $42.3 \%$ of the total variation of the scale. Results presented in table 4-2.

\section{Table 2. Results of exploratory factor analysis for Reasons for Internet Use Scale}

\begin{tabular}{|c|c|c|c|c|c|c|c|c|c|}
\hline \multicolumn{10}{|c|}{ Total Variance Explained } \\
\hline \multirow[t]{2}{*}{ Component } & \multicolumn{3}{|c|}{ Initial Eigen values } & \multicolumn{3}{|c|}{ Extraction Sums of Squared Loadings } & \multicolumn{3}{|c|}{ Rotation Sums of Squared Loadings } \\
\hline & Total & $\begin{array}{ll}\% & \text { of } \\
\text { Variance } & \end{array}$ & Cumulative \% & Total & $\begin{array}{ll}\% & \text { of } \\
\text { Variance } & \end{array}$ & Cumulative \% & Total & $\begin{array}{ll}\% & \text { of } \\
\text { Variance } & \end{array}$ & Cumulative \% \\
\hline 1 & 4.972 & 29.249 & 29.249 & 4.972 & 29.249 & 29.249 & 4.383 & 25.782 & 25.782 \\
\hline 2 & 2.219 & 13.054 & 42.304 & 2.219 & 13.054 & 42.304 & 2.809 & 16.521 & 42.304 \\
\hline 3 & 1.584 & 9.320 & 51.623 & & & & & & \\
\hline 4 & 1.431 & 8.420 & 60.044 & & & & & & \\
\hline 5 & 1.270 & 7.472 & 67.516 & & & & & & \\
\hline 6 & 1.083 & 6.373 & 73.889 & & & & & & \\
\hline 7 & .788 & 4.632 & 78.522 & & & & & & \\
\hline 8 & .732 & 4.305 & 82.826 & & & & & & \\
\hline 9 & .654 & 3.847 & 86.673 & & & & & & \\
\hline 10 & .446 & 2.623 & 89.296 & & & & & & \\
\hline 11 & .394 & 2.317 & 91.613 & & & & & & \\
\hline 12 & .358 & 2.103 & 93.716 & & & & & & \\
\hline 13 & .318 & 1.869 & 95.585 & & & & & & \\
\hline 14 & .232 & 1.365 & 96.950 & & & & & & \\
\hline 15 & .202 & 1.190 & 98.140 & & & & & & \\
\hline 16 & .188 & 1.104 & 99.244 & & & & & & \\
\hline 17 & .128 & .756 & 100.000 & & & & & & \\
\hline
\end{tabular}

According to the second table (4-3) all of the items located in relevant dimensions.

Table 3. Rotated component matrix

\begin{tabular}{|c|c|c|}
\hline \multicolumn{3}{|c|}{ component } \\
\hline & 1 & 2 \\
\hline b1 & .344 & .429 \\
\hline b2 & -.077 & .785 \\
\hline b3 & -.419 & .422 \\
\hline
\end{tabular}




\begin{tabular}{lll}
\hline $\mathbf{b 4}$ & .622 & -.172 \\
$\mathbf{b 5}$ & -.640 & .231 \\
$\mathbf{b 6}$ & .541 & -.034 \\
$\mathbf{b 7}$ & -.416 & .292 \\
$\mathbf{b 8}$ & .114 & .721 \\
$\mathbf{b 9}$ & -.469 & .535 \\
$\mathbf{b 1 0}$ & .493 & -.209 \\
$\mathbf{b 1 1}$ & -.141 & .691 \\
$\mathbf{b 1 2}$ & .736 & -.067 \\
$\mathbf{b 1 3}$ & .712 & .089 \\
$\mathbf{b 1 4}$ & .571 & .051 \\
$\mathbf{b 1 5}$ & .511 & -.037 \\
$\mathbf{b 1 6}$ & -.734 & .119 \\
$\mathbf{b 1 7}$ & -.387 & .551 \\
\hline
\end{tabular}

\subsubsection{Convergent Validity and Discriminant Validity}

To evaluate validity of Reasons of S.N.S Use Scale convergent and discriminated validity was assessed. Result presented in table 4.

Table 4. Convergent Validity and Discriminant validity of Reasons of S.N.S Use Scale

\begin{tabular}{lcllllll}
\hline & & \multicolumn{2}{l}{ Discriminant validity } & \multicolumn{3}{l}{ Convergent validity $^{\mathbf{a}}$} \\
Dimensions & Items & $\begin{array}{l}\text { Range } \\
\text { correlation }\end{array}$ & $\begin{array}{l}\text { Scaling } \\
\text { (percent) }\end{array}$ & success & $\begin{array}{l}\text { Range } \\
\text { correlation }\end{array}$ & $\begin{array}{l}\text { Scaling } \\
\text { (percent) }\end{array}$ & success \\
\hline $\begin{array}{l}\text { Positive } \\
\text { reasons }\end{array}$ & 6 & $0.175-0.402$ & $6 / 6(100)$ & $0.643-0.758$ & $6 / 6(100)$ \\
$\begin{array}{l}\text { Negative } \\
\text { reasons }\end{array}$ & 11 & $0.057-0.54$ & $8 / 11(73)$ & $0.316-0.831$ & $9 / 11(82)$ \\
\hline
\end{tabular}

a- Number of correlations between items and hypothesized scale corrected for overlap $\geq 0.4 \quad /$ total number of convergent validity test.

b- Number of convergent correlations significantly higher than discriminant correlations / Total number of correlations.

These finding show that scaling success rate for convergent validity is $100 \%$ for positive reasons and $82 \%$ for negative reasons.

The success rate for discriminant validity of Reasons for S.N.S Use in $82.35 \%(14 / 17)$ As the results indicate overall validity for the static method of S.N.S use is acceptable (this convergent and discriminant validity) Method based on fayers, 2000)

\subsection{Scoring}

This scale includes 17 Likert type questions with four point scale, 1: strongly disagree and 4 strongly agree. The Scale has 7 positive reasons for S.N.S and 10 negative one, this scale has two dimensions: positive and negative reason for S.N.S Use, according to factor analysis. Total score for each dimension maybe computed by summing all items (in each dimension).

Positive reason for S.N.S Use may be computed by summing items scores: $1,2,3,8,9,11,17$ and negative reason for S.N.S use May be computed by summing item score:4,5,6,7,10,12,13,14,15,16.The mean \pm SD for positive reasons in this survey was $17.70 \pm 4$.9. The mean \pm SD for negative reasons of S.N.S Use in this study was $23.9 \pm$ 9.33. Time required for this scale is 5 minute.

\subsection{Score Interpretation}

A higher score in each dimension indicated a greater degree of S.N.S Use for positive or negative reasons. 


\section{Discussion}

Reasons of Social Networking Sites Use scale as the results indicate showed acceptable reliability and validity with Iranian students. The results of exploratory factor analysis indicated two aspects, positive reasons and negative reasons, explain total variation acceptably.

\section{Conclusion}

A number of researchers have noted the need for standard scales to assess internet behaviors along with more empirical evidence. Reasons of Social Networking Sites Use scale could be a helpful device to evaluate PIU and its related behaviors. It is important that validity and reliability of this scale be measured by other means. It is also suggested that the scale, being evaluated on more diverse population.

\section{References}

Amiel, T., \& Sargent, S. L. (2004) Individual difference in Internet usage motives. Computers in Human Behavior, 20, 711-26.

Caplan, S. E. (2002). Problematic Internet use and Psychological well-being development of a theory based cognitive-behavioral measure. Computers in Human Behavior, 18, 533-575.

Caplan, S. E. (2003). Preference for online social interaction: A theory of problematic Internet use and psychological we-being. Communication Research, 30, 625-648.

Coplan, S. E. (2007). Relation Among Loneliness, social Anxiety and Problematic Internet Use. Cyber Psychology \& Behavior.

Davis, R. A. (2001). A cognitive-behavioral model of pathological Internet use. Journal of Communication, 17, 187-195.

Davis, R. A. Flett, G. L., \& Besser, A. (2002). Validation of a new measure of problematic Internet use: Implications for pre-employment screening. Cyber Psychology \& Behavior, 5, 331-346.

Ehrenberg, A., Juckes S., White K. M., \& Walsh, S. P. (2008). Personality and self-esteem as predictors of young peoples technology use.Cyber Psychology \& Behavior, 11, 739-41.

Fayers, P. M., \& Machin, D. (2000). Assessment Analysis an Interpretation.Quality of Life, 50-70.

Hamburger, Y. A., \& Ben-Artzi, E. (2000). The relationship between extraversion and neuroticism and the different uses of the Internet. Computers in Human Behavior, 16, 441-49.

Hardie, E., \& Tee, M. (2001). Execessive Internet use: the role of personality, loneliness and social support networks in Internet addiction. Australian Journal of Emerging Technology and Society, 5, 34-47.

Lennug, L. (2011). Loneliness, social support and preference for online social interaction: The mediating effect of identity experimentation online among children and adolescence. Chinese Journal of Communication, 4, 381-399.

Lin, H. F. (2006). Understanding behavioral intention to participate in virtual communities. Cyber Psychology \& Behavior, 9, 540-7

McEllroy, J. C., Hendrickson, A. R., Townsend, A. M., \& Demarie, S. M. (2007). Dispositional factors in internet use: Personality versus cognitive style. MIS Quarterly, 31, 809-20.

Morahan-Martin, J., \& Schumacher, P. (2003) Loneliness and social uses of the Internet. Computers in Human Behavior, 19,659-671.

Pack, N., Kee, K. F., \& Valen, Z. M. A. (2009). Being immersed in social Networking Environment: FAceboo groups, Uses and Gratifications and social outcome. Cyber Psychology \& Behavior, 12.

Ridings, C. M., \& Geten, D. G. (2007). Virtual community attraction: Why people hang out online. Journal of Computer Mediated Communication. Retrieved from http://jcmc.indiana.edu/vol10/issue1/ridings-geten

Walsh, S. P., White, K. M., \& Young, R. M. (2007). Young and connected: Psychological influences of mobile phone use amongst Australian youth. In: Goggin G, Hjorth L, eds. Mobile Media 2007: Preceedings of an international conference on social and cultural aspects of mobile phones, media and wireless technologie, Sydney: University of Sydney, 125-34.

Wilson, K., Fomasier, S., \& White, K. M. (2010). Psychological Predictors of young adults: use of social networking sites. Cyberpshychology, Behaviour, and Social Networking, 13(2). 


\section{Appendix}

\section{Appemdix A}

Reasons (positive and negative) for internet use scale

1- I use S.N.S to communicate with friends and family. $(+)$

2- I use S.N.S for required course work. $(+)$

3- I use S.N.S for recreation. $(+)$

4- I feel relaxed just by using S.N.S. (-)

5- I use S.N.S to find job most of time. (-)

6- I make new friendship just by using S.N.S (-)

7- I talk to others who share common interests only through S.N.S. (-)

8- I use S.N.S for staying abreast of new development in areas of interests. $(+)$

9- I use S.N.S for sharing ideas or fantasies. (+)

10- I use S.N.S for wasting time. (-)

11- I use S.N.S for finding information for own use. $(+)$

12- I use S.N.S seeking emotional supports. (-)

13- I use S.N.S for gambling (-)

14- I use S.N.S for net resources

Intended for adults only. (-)

15- I use S.N.S for games. (-)

16- I just use S.N.S for virtual Reality. (-)

17- I use S.N.S for browsing. (+)

+ marks positive reasons

-marks negative reasons

\section{Copyrights}

Copyright for this article is retained by the author(s), with first publication rights granted to the journal.

This is an open-access article distributed under the terms and conditions of the Creative Commons Attribution license (http://creativecommons.org/licenses/by/3.0/). 